\title{
The Mediating Role of Electronic Performance Monitoring in the relationship between Personality Traits and Work Passion
}

\section{Fizza Hussain}

NUST Business School, National University of Sciences and Technology, Pakistan

Mumtaz Ali Memon*

NUST Business School, National University of Sciences and Technology, Pakistan

Hadia Naeem

NUST Business School, National University of Sciences and Technology, Pakistan

\section{Shumaila Hafeez}

NUST Business School, National University of Sciences and Technology, Pakistan

*Corresponding author: mumtazutp@gmail.com

\begin{abstract}
This study aims to study the relationship between personality traits (conscientiousness and extraversion), electronic performance monitoring (EPM) and work passion. In addition, it investigates the mediating role of EPM between personality traits and work passion. Data was collected from 105 employees working in call centers throughout Pakistan. Partial least squares structural equation modeling (PLS-SEM), using SmartPLS 3.0, was performed to test the hypothesized model. The results showed that consciousness and extraversion have a positive impact on EPM and work passion. In addition, EPM acts significantly as a mediator between personality traits and work passion among call center employees. This is the first study that examines the mediating role of EPM in the relation between personality differences and work passion. The results of the study would help Asian human resources professionals effectively perform human resources functions, such as employee staffing, training, and performance management. Implications for managers and recommendations for future studies are proposed.
\end{abstract}

Keywords: Conscientiousness, Extraversion, Electronic performance monitoring, Work passion 


\section{Introduction}

In today's increasingly technology dependent work, almost every inch of work from a simple touch of keyboard to large robots is continuously generating data and leaving prints behind to monitor and analyze them. Organizations sometime use electronic instruments such as radio, video devices, computer software and systems to monitor and evaluate employee performance (Claypoole et al., 2019). Starting from telephone monitoring; now firms can monitor each aspect of employees including their performance, behavior and even mental state through different sensors and devices. This advancement in technology, reduction in costs, and shift of work to cyber workspace has made it inevitable for the organizations to use electronic monitoring (Becker et al., 2020). Such as, in call centers, performance is monitored electronically with more invasive technologies other than computer monitoring (Jeseke \& Santuzzi, 2015).

To understand electronic performance monitoring (EPM), it is important for the researchers and organizations to understand how it differs from traditional monitoring and what benefits and concerns are associated with it. In traditional systems, data was collected by supervisors, their attention being limited resulted in collecting data only on specific behaviors whereas EPM allows for data to be continuously monitored not only for specific workplace incidents, but also internal states and private behaviors can also be monitored. Employers use novel tools to monitor employee thoughts, attitudes, and intentions about the work he is currently doing (White et al., 2020). However, recent research has raised some concerns of deviant behaviors employees follow when they feel their performance is overly controlled by electronic monitoring systems (Fusi \& Feeney,2018).

Previous research highlight that the behaviors and attitudes of individuals are driven by their personality traits (Athota et al., 2020). Personality traits refers to the dispositions and internal strategies that have an impact on individual's behaviors, emotions, and thoughts (Gridwichai et al., 2020). However, personality being one of the main factors suggests that a person's specific characteristics and style has the ability to change the reactions towards EPM and how it is perceived. For example, when the employees perceive the purpose of EPM is for collecting data and facilitating their performance, satisfactory behaviors are reported (Robinson, 2020). In a study, Jahagirdar and Bankar (2020) investigated the individual's perceptions towards the use of EPM and found that when EPM was incorporated for improving and supporting performance it was positively related to employee performance. In the light of past research, this study will assess two personality traits of Conscientiousness and Extraversion; these traits have shown strong influence on employee's attitude towards work performance (Sari, 2020). Those who are high in conscientious are more cautious and tend to complete tasks more efficiently, this points out an intrinsic disposition which enables them to view EPM as developmental, thereby negating negative feelings of distrust, privacy invasion and enhancing passion and commitment. Similarly, extraversion and emotional stability have shown positive attitudes and reactions towards EPM (Ravid \& Behrend, 2020). In addition to this, it has been identified that in comparison to introverts, extroverts are more likely to experience higher level of positive feelings and reactions towards electronic monitoring and social presence (Claypoole et al., 2018). 
The purpose of this study is to examine the causal relationship between personality traits (i.e., conscientiousness and extraversion), perceived EPM and work passion. The study also aims to investigates the mediating role of perceived EPM between personality traits and work passion in the context of call centers. In achieving the objectives of the study, this research not only contributes the existing literature on EPM, work passion and personality traits, but it also responds several calls for research. Feenay (2018) suggested to study the impact of technology adoption of HR on employee's psychological and work outcomes. Some other recent studies that call for the research on the EPM and its effect on job performance and employee's attitude (Story \& Castanheira, 2020; Umar et al., 2020; Becker et al., 2019; Yost et al., 2019). Additionally, attitude derived from the individual personalities is identified as a less studied area with respect to the EPM because many recent studies have suggested to identify the role of different personalities in perceiving the role of EPM (e.g., Claypoole \& Szalma, 2019; Connelly et al., 2020).

A recent study has suggested to identify the variable that would be determinant of passion and examine its mediating effect on the relationship between personality and work passion (Dalpe et al., 2019). Pollack et al. (2020) defined passion as a strong tendency towards something one loves, values, and gives importance to. Passion develops with the interaction of environment, personal differences and activity performed. As a result, activity becomes passionate if the individual needs within a certain environment are fulfilled. Lastly, Ravid et al. (2020) recommended future research about interaction of personality traits with characteristics of EPM and how they impact on reaction of individuals. Thus, a noticeable gap is evident for studying the mediating role of EPM on the relationship of personality traits and work passion.

The findings of the study will be useful for the organizations in identifying those personalities which carry positive impact by perceiving the EPM as development and do not show resistance towards the use of EPM in an organization. With this study, organizations will be able to institutionalize the use of EPM as developmental by considering given personalities in the process of employee selection for getting the desired behavior.

\section{Theoretical Background and Hypothesis Development}

\section{Self-Determination Theory}

Self-determination theory (Weiner, 1990) is one of the most prominent theory to study human motivation. SDT assumes that humans are active species, motivated to collect and integrate knowledge from their social and physical environments (Ryan, 1995). SDT considers human behavior as proactive and growth oriented, both active and passive sides are the result of interaction between human basic psychological need and support sources or opposing forces in social environments (Vansteenkiste \& Ryan, 2013). According to SDT individual's motivation to pursue a task can be intrinsic or extrinsic (Deci \& Ryan, 2008). Intrinsic motivation possesses an individual's desire for autonomy, competence, and relatedness. Whereas the extrinsic motivation involves attaining rewards, career development, positive assessment and to avoid punishment (Liang et al., 2013). There are many motivation theories that are frequently used to study the acceptance and usage of systems in the organizations (Chung \& Kim, 2014). We therefore apply SDT in the workplace context for the following reasons. 
SDT being the best detailed framework to link the intrinsic/extrinsic motivation and positive outcomes (Olafsen et al., 2015). SDT also enables researchers to study the individual differences and interpersonal settings that are need supportive and act as a motivator for positive work outcomes (Deci \& Ryan, 2012). This theory conceptualizes internal locus of causality that is influenced by personality. The I-PLOC predicts effort and enjoyment which in turn shows positive outcomes. Our study examines two personality traits Extraversion and Conscientiousness. According to Turban et al. (2007) Extroverts are more likely to focus attention on what is valuable in the task and align task requirements with their values.

Similarly, conscientious individuals are more likely to accept and take owner ship of tasks that are required for success. Consequently, the psychological needs for competency and relatedness are attained by the employees. Another study by Landry et al. (2018) provided empirical evidence that when the job characteristics are positively related to fulfillment of psychological needs, it positively impacts work intentions indicating Work Passion. Based on the above discussion, SDT theory was adopted to provide support for the individual differences and how these differences perceive EMP and its impact on Work Passion.

\section{Conscientiousness and work passion}

People who fall under the category of conscientiousness are more flexible and prone to conform to rules, norms, and environment which their organization requires them to achieve the goals and objectives (Baptiste, 2018). With this kind of personality comes passion for work. Work Passion can be defined as strong inner motivation, positive state of mind and drive to achieve goals, get appraisals that helps organization to grow as well as the individuals. Conscientiousness and Work Passion have positive impact on one another. Where Conscientiousness makes individuals reliable, efficient, and responsible consequently the Work Passion gives them the attitude to be more successful and goal oriented. ( Kreil et al., 2021). The hypothesis is already established in an existing literature (Dalpé at al., 2019). If a person has this personality, it is positively associated with Work Passion.

\section{Extraversion and work passion}

Extroverts have high social potency which means they are good at dealing with others and are more decisive and assertive than non-extroverts. They have strong drive to achieve their goals and are good at persuasion; they motivate others to perform their tasks more effectively with their easy-going personality (Blickle et al., 2015).

Extroverts are good at people-oriented jobs where they can one on one interact with people they are working with or the customers, they explain better, talk better so they dominate in this category. The hypothesis is already established in existing literature (Dalpé at al., 2019). Extraversion and Work Passion have positive relation because passion for work can be found strongly in extroverts as they strive for novelty and the people who possess optimistic and enthusiastic traits work better than those who does not have them, a psychologically sound head can perform more effectively they not only fulfill job requirements but also show job satisfaction. (Kreil et al., 2021). 


\section{Conscientiousness and EPM}

Costa et al. (1991) described conscientious as a personality that strives to be logical and focus on foresightedness. They are very careful and are not much concerned about electronic or social media monitoring as detrimental or harmful (Schneider et al., 2015). Another study investigated that when negative relationship exists between justification of social media perception and privacy invasiveness people with conscientious trait have the ability to mitigate this relationship because this personality accepts and agrees with rules and regulations of their organization, but their hypothesis could not support this relationship (Sayre \& Dahlin, 2016). Some researchers suggest that Conscientious individual feel happy when they perceive monitoring may enhance their performance and communication, hence they show more positive attitude towards it.

H1a Conscientiousness has positive relation with perception of EPM as development.

\section{Extraversion and EPM}

Now, when we talk about Extraversion, these individuals are very hopeful and outgoing hence they feel energetic from engaging in social activities (Junglas et al., 2008). One study analyzed that this personality trait does not consider control of personal information as detrimental for itself (Stone, 1986). Another study assumed that individuals having this trait may not be much sensitive to social media monitoring (Sayre \& Dahlin, 2016). Individual with high Extraversion trait perceive electronic monitoring fair as compared to individuals low in Extraversion, hence personality differences have different impact on how they perceive electronic monitoring and their attitude towards it (Zweig \& Webster, 2003).

H1b Extraversion has positive relation with perception of EPM as development.

\section{EPM and Work Passion}

Electronic monitoring is inherently perceived by individuals to have a negative impact on employee attitudes and behaviors (Sherif \& Jewisimi. 2018). However, recent research has shown some positive effects under certain circumstances. Studies proposed framework to accommodate many electronic monitoring forms based on its characteristics including its purpose, transparency and invasiveness (Tomczak \& Behrend, 2019). Each characteristic has different impact on the employees being monitored. For example, a study conducted on EPM functions and employee attitudes hypothesized that if people perceive monitoring technology as useful, this has a positive impact on work attitudes (Abraham et al., 2019). Similarly, when employees perceive the objective of electronic monitoring as to enhance their productivity and a chance to increase their performance (such as developmental EPM), they are more likely to accept the technology (Laird et al., 2018).

Based on prior research, some evidence exists suggesting positive relationship between EPM perceived as developmental and feelings of job satisfaction, commitment, and reciprocal feelings of obligation towards the organization in the form of passion (Ravid et. Al, 2019). Karim (2015) conducted a research experiment that showed that EPM for developmental purpose communicated employees that organization is committed to enhance their growth, which in return lead to positive workplace attitudes thus 
providing significant evidence for a relationship between EPM perceived as developmental and Work Passion. We therefore hypothesize that:

H2 EPM perceived as developmental has a positive impact on work passion.

\section{EPM as Mediator}

Taking into consideration that Conscientiousness is not negatively related to the EPM perceived as developmental (Robinson, 2020; Chen \& Ross, 2007), shows more acceptance of EPM and considers EPM as an accurate way of assessing the performance (Brown et al., 2012), and EPM is positively related to the Work Passion as it increases the employee performance and productivity (Claypoole \& Szalma, 2019). It has been suggested that purpose of electronic monitoring is to influence employees' behaviors and attitudes in negative and positive both ways (Jeske \& Santuzzi, 2013). Therefore, it is premise that if it is taken as developmental, employee would display positive attitudes. It is recommended that positive attitudes can be enhanced using the EPM as developmental and learning purpose rather than deterrence (Tomczak et al., 2018). In a recent paper, it is expected that developmental EPM mediates the relationship of Conscientiousness and behaviors with positive influence (Ravid et al., 2020; Yost et al., 2019). As the behaviors of such personality characteristics tend to positively change if it perceives EPM as developmental. Employees with such personality characteristics show more positive attitudes when being monitored electronically (Zweig \& Webster, 2003).

According to SDT, humans feel self-motivated and self-determined when their psychological needs are met such as competence and autonomy (Rigby \& Ryan 2018), When people with such traits such as result-oriented, detail-oriented, responsible and diligent work in social context where EPM is communicated and perceived as developmental results into increased intrinsic motivation (Deci, 1971). Therefore, we hypothesize the following:

H3a EPM perceived as developmental mediates the relationship between Conscientiousness and work passion of employees.

According to the literature, Extroverts are more comfortable working in EPM settings. Therefore, Extraversion has more positive relationship with EPM (White et al., 2020) and perceives such monitoring as fairer (Zweig, \& Webster, 2003). It has been identified that Extraversion trait is more acceptable of EPM as developmental and the managerial justifications of the use of EPM (Chen \& Ross, 2007). It is identified that extroverts are more related to the vigilance performance which is the result of the consistency and passion (Claypoole et al., 2018). It has also been identified in many studies that EPM is positively related to the employee satisfaction (Samaranayake \& Gamage, 2011) and job satisfaction when employees have positive opinions about EPM (Furnham \& Swami, 2015). Previous studies have demonstrated that employees high in Extraversion are more likely to produce the positive attitudes when indulge in developmental EPM (Ravid, 2020; Furnham \& Swami, 2015). This indicates that employee high in Extraversion perceives EPM as an entity which will uplift the work quality and is related to the productive behaviors (Samaranayake \& Gamage, 2011). 
According to the previous studies, SDT is based on the study of human behavior, mainly focused on internal and cognitive variables such as motives, desires (Krupic \& Corr, 2020). whereas the three fundamentals of Self-Determination Theory are autonomy, competent and self-efficacy (Alessandri, 2020). As mentioned in the operational definition of Extraversion, such characteristics support this kind of human behavior. A greater degree of self-determination is reflected in the highest level of intrinsic motivation (Pietrabissa et al., 2020) and it is identified that Extroverts more positively related to the intrinsic motivation then extrinsic motivation (Ariani, 2013). Thus, according to SDT, the EPM perceived as developmental is expected to increase the intrinsic motivation of extroverts and as a result employee responds with increased Work Passion. This theory further supports this stance because extroverts possess such characteristics which are desirable to attain three fundamentals of the SDT.

H3b EPM perceived as developmental mediates the relationship between extraversion and work passion.

Figure 1: Conceptual Frmaework

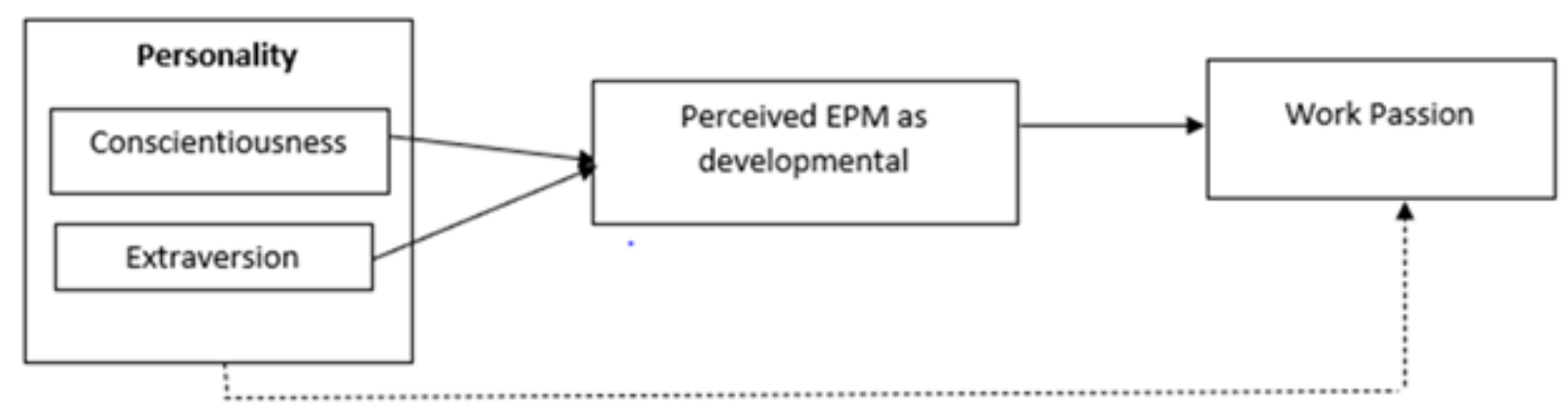

\section{Methods}

\section{Context}

The data was collected from the call centers of different cities all-around Pakistan i.e., Islamabad, Rawalpindi, Karachi, Lahore Peshawar. These cities were selected because most of the call center companies are operating in Karachi, Lahore, Islamabad, and Rawalpindi (Durrani, 2018). The BPO industry of Pakistan is seen as an emerging source of increasing employment and comprises of massive economic potential (Baloch, 2018). The target population was the employees of call centers who were working at the frontline and dealt directly with customers by using any electronic medium. Call-center is a context, where performance can easily be measured using EPM (Yost et al., 2019) and employees work in surveillance and high-pressure environment (Story \& Castanheira, 2020). Call centers are notably known as "whitecollar sweatshops," where workers earn low wages and perform under stressful circumstances (Clark et al., 2019). Hence, this context was more appropriate for the proposed study. 


\section{Instrument}

For this study, 16-item questionnaire was used to measure the Conscientiousness, Extraversion, EPM as developmental and Work Passion. The scales were adopted from the previous measures. The Conscientiousness was measured by using four items adapted from the Donnellan, Oswald, Baird, and Lucas (2006) with reliability 0.71 (Zacher, 2014). Conscientiousness refers to the individual comprising of these three characteristics i.e., organization, productivity, and responsibility (DeYoung et al., 2007; McCrae \& Costa, 2008). The sample item from the four-item scale of Conscientiousness includes "I always remember to put things back in their proper place". Extraversion was measured using 4-items scale adapted from the Donnellan, Oswald, Baird, and Lucas (2006) with reliability 0.85. Previous literature on personality has identified that the sociability, energy level and assertiveness are central facets to the Extraversion (Lucas et al., 2008; McCrae \& Costa, 2008).

The sample item of Extraversion includes "I talk a lot". EPM was measured by using 3-items scale adopted from Karim (2015) and originally developed by Wells et al. (2007). The developmental purpose of EPM includes training needs, feedback and identification of strengths and weakness of employees (Cleveland et al., 1989; Wells et al., 2007). The sample item of EPM includes "The company uses the call monitoring system to help me perform my job better".

The Work Passion was measured by using 5-items scale adopted from Pollack et al. (2020) further used by Haq et al. (2019) but originally developed by Baum and Locke (2004). Work Passion refers to the positive feeling of individuals for work (Pollack et al., 2020), The sample item includes "I love to work". The items of each variable were measured by using 5-point Likert scale from 1 (strongly disagree) to 5 (strongly agree) and listed in the Appendix.

Pilot Testing. A pilot test was conducted with three respondents to identify any problems before starting the data collection process. The link was sent to three different people, and they were requested to give feedback after filling the survey form. The feedback was based on asking questions regarding facing any difficulty while filling out the form or finding any ambiguities. In response to such questions two respondents filled it without any difficulty. The second respondent was not able to submit due to some internet issue and refused to fill it again. Otherwise, there was no issue regarding any question.

\section{Sampling and Data Collection}

To collect data, snowball sampling was used because at times of covid-19, this sampling was more appropriate than other sampling techniques. The minimum sample size, decided for this study was 160 due to time constraint, as taken by similar studies, conducted in similar context, and supported by quantitative methodologist (Story \& Castanheira, 2020; Memon et al., 2020). However, we only managed to get 141 responses due to uncertain conditions of COVID-19.

The data was collected from the employees of call centers. For the purpose of data collection, close ended questionnaires were used by adopting the items from other studies. To collect data, an electronic email survey was developed on google forms because this offers respondents to fill in the survey form as per their own convenience 
(Heerwegh, 2009). Along with this, electronic email is an appropriate way for collecting data from the diverse geographical areas (Saunders et al., 2007) and particularly at times of covid-19. The link address of the survey with the cover letter was sent to 400 plus employees. However due to the shortage of time, we only managed to get 141 responses in a period of 1.5 month. Out of 141 responses, 36 samples were eliminated from the study, some of the samples had less than 1 year of experience and few of them had many missing values. The former one had 24 responses and latter one comprised of 10 responses. Therefore, the result of the tested hypothesis was based on the 105 responses.

Table 1: Demographic profile of Respondents

\begin{tabular}{llcc}
\hline Demographics Variables & Categories & Frequencies & Percentages \% \\
\hline \multirow{3}{*}{ Gender } & Male & 83 & 79 \\
& Female & 22 & 21 \\
Age & Less than 20 years & 3 & 2.9 \\
& 20 to 30 years & 84 & 80 \\
\multirow{3}{*}{ Work Experience } & 31 to 40 years & 18 & 17.1 \\
& 1 to 5 years & 78 & 74.3 \\
& 6 to 10 years & 23 & 21.9 \\
& above 10 years & 4 & 3.8 \\
\hline
\end{tabular}

\section{Common Method Bias}

In survey-based research, Common method bias in one of the major concerns (Schwarz et al., 2017), it measures the degree of covariance among the items because the data source was single (Hair et al., 2014). To address this issue, procedural approach was used which was pilot tested to avoid the confusion at time of data collection, clear instructions were given, and the anonymity and confidentiality was ensured (Schwarz et al., 2017). CMV of this study was 25.952 by using Harman-Single Factor through SPSS, that is far less than $40 \%$ as recommended by Fuller et al. (2016). It is concluded that data has less variation and less bias due to instrument issue hence, data was fair to be analyzed further.

\section{Data Analysis and Results}

To test the hypothesis of our study we used the Vigor and commonly used method Partial least squares equation modeling through SmartPLS 3.3.2 by Ringle et al. (2015). We wanted to predict incremental factor of our study. This study perceived EPM as developmental as a mediator between Personality and passion. PLS-SEM is useful to predict this relationship (Hair et al., 2014), hence we used it in our study. For the study we adopted structural equation modeling and went through two stages to achieve the results. The first one was analyzing measuring model where we analyzed internal consistency reliability and validity and the other one is structural model where we tested our hypothesis, suggested by Andersen and Gerbing (1988). 


\section{Measurement Model}

First, we analyzed measurement model. From this model we assessed Internal Consistency \& Reliability (ICR), Indicator Reliability (IR), Convergent Validity (CV) and Discriminate Validity (CV). ICR Measures through composite reliability (Hair et al., 2014), in smart PLS which should lie between 0.7 to 0.9 and then we can declare it as satisfactory (Richer et al., 2016). Our study results showed that composite reliability of all our constructs lied between this range (0.7-0.9), showing high level ICR, Conscientiousness was 0.829 , EPM was 0.860 , Extraversion was 0.844 and finally WP was 0.866 . The next one is convergent validity and according to Hair et al. (2016, p.112) $\mathrm{CV}$ analyzes "the extent to which a measure correlates positively with alternative measures of the same construct". It can be measured through average variance extracted (AVE) which should be equal or higher than 0.5 and outer loading which must be equal or higher than 0.708 (Avkiran, 2018). All constructs of the study fulfilled the criteria such as AVE of Conscientiousness was 0.550, EPM was 0.673, Extraversion was 0.579, and finally WP was 0.565 . It showed that our factors are linked with same variable. All result of ICR and CV are given in Table 2. Finally, the last step in measuring model was discriminate validity (DV). It is defined by Hair et al. (2017) as the degree to which variables in the model are different from each other. To find DV, Fornell and Larcker (1981) criteria was used where we compared constructs' correlation and their square root of AVE such that square root of AVE of variables must be higher than the correlation value of that variable. Our result of DV fulfilled the criterion which is shown in Table 3. For first part of structural equation modeling our data remained reliable and valid.

Table 2: Internal Consistency and Reliability and Convergent Validity

\begin{tabular}{lcccc}
\hline Constructs & Items & Loading & AVE & CR \\
\hline Conscientiousness & CON1 & 0.608 & 0.55 & 0.829 \\
& CON2 & 0.770 & & \\
CON3 & 0.834 & & \\
Electronic Performance Monitoring & CON4 & 0.737 & & \\
& EPM1 & 0.879 & 0.673 & 0.86 \\
& EPM2 & 0.747 & & \\
Extraversion & EPM3 & 0.828 & & \\
& EXT1 & 0.654 & 0.579 & 0.844 \\
& EXT2 & 0.865 & & \\
Work Passion & EXT3 & 0.677 & & \\
& EXT4 & 0.825 & & \\
& PAS1 & 0.695 & 0.565 & 0.866 \\
& PAS2 & 0.791 & & \\
& PAS3 & 0.781 & & \\
& PAS4 & 0.68 & & \\
& PAS5 & 0.803 & & \\
\hline
\end{tabular}


Table 3: Discriminate Validity

\begin{tabular}{lcccc}
\hline Constructs & Conscientiousness & EPM & Extraversion & Work Passion \\
\hline Conscientiousness & $\mathbf{0 . 7 4 2}$ & & & \\
EPM & 0.445 & $\mathbf{0 . 8 2 0}$ & & \\
Extraversion & 0.322 & 0.413 & $\mathbf{0 . 7 6 1}$ & \\
Work Passion & 0.324 & 0.311 & 0.369 & $\mathbf{0 . 7 5 2}$ \\
\hline
\end{tabular}

\section{Multicollinearity}

If different variables present same affect, then it is considered as multicollinearity error. To assess it, variance inflation factor (VIF) was used that must not be greater than 5.0 otherwise it would be considered as collinearity issue. (Hair et al., 2014). Our findings confirmed this criterion, as shown in Table 5, where all values are less than 5.0 hence, there was no issue of collinearity.

\section{Structural Model}

To analyze causal relationships between variables structural modeling was used. For this purpose, by following Hair et al. (2014), we re-sampled 5000 the data in bootstrapping techniques that estimated the hypothesized model statistical significance. Our study structural model results are shown in Fig 2. Results indicate that Conscientiousness (H1a: $\beta=0.348, t=3.838, P=0$, LL: +0.167 , UL: +0.471 ) had a significant positive association with EPM as hypothesized. Other personality trait of Extraversion (H1b: $\beta=0.301, \mathrm{t}=3.956, \mathrm{P}=0, \mathrm{LL}:+0.145$, UL: +0.403 ) also had a significant positive impact on EPM as hypothesized. Further, EPM $(\mathrm{H} 2: \beta=0.311, \mathrm{t}=$ 4.093, P $=0$, LL: +0.182 , UL: +0.388 ) had a positive association with Work Passion as hypothesized. Then we analyzed the mediating effect of EPM on the relationship between Conscientiousness and Work Passion (H3a) and on the relationship between Extraversion and Work Passion (H3b).

We followed Nitzl et al. (2016) to test mediating effect of our variable by bootstrapping indirect effect. It is shown in Table 4. We had two hypotheses for mediation which were supported. EPM was a mediator in the relationship between Conscientiousness and Work Passion (H3a: $\beta=0.108, t=2.500, p=0.012$, LL: +0.023 , UL: +0.177 ). Also, EPM was a mediator in the relationship between Extraversion and Work Passion (H3b: $\beta=0.094, t=2.468, p=0.014, \mathrm{LL}:+0.023$, UL: +0.150$)$. It is concluded that our all hypothesis were supported.

As recommended by Hair et al. (2017), any study must include the results of Coefficient of determination, and effect size. All these values are given in Table 5. It is represented by $\mathrm{R} 2$ and referred to as independent variable explanatory power w.r.t dependent variables. R2 for our study showed that Conscientiousness and Extraversion trait of employees, perceived 0.279 EPM as developmental that enhanced 0.097 of their passion for work. Then we analyzed effect size that is contribution of independent variable for R2 of dependent variable and denoted by f2giving small, medium, and large indication of effect size if $f 2$ will be $0.02,0.15$ and 0.35 , respectively. $f 2$ of our study showed that Conscientiousness has a medium effect on EPM $(f 2=0.151)$, EPM has small effect on Work Passion $(\mathrm{f} 2=0.107)$ and Extraversion has small impact on EPM $(\mathrm{f} 2=0.113)$. 
For assessing relevance of prediction blindfolding technique is used. Recommended by Hair et al. (2017) its value must be greater than zero, for quality predictive relevance. It is represented by Q2. For our study, its value lied inside the required range. Q2 of EPM is 0.146 and Work Passion was 0.039 that was more than zero shown in Table 5.

Figure 2. Structural Model

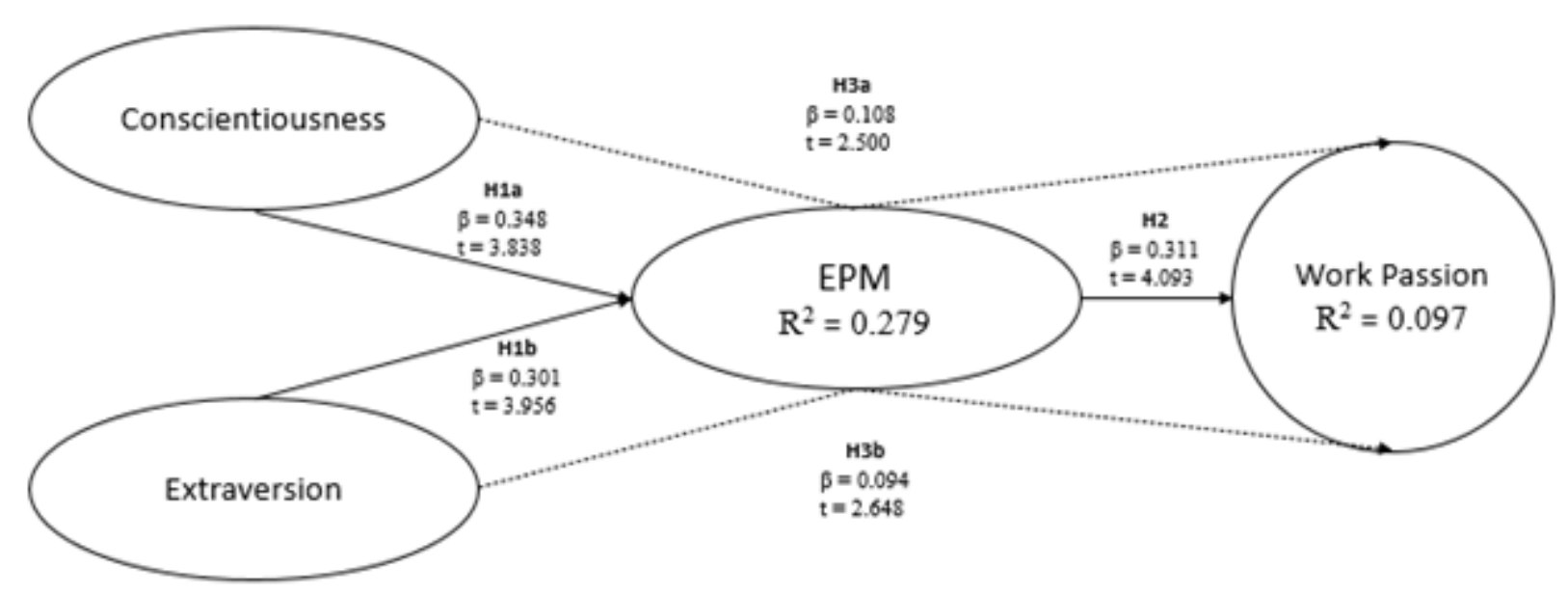

Table:4 Results of Structural Model Assessment

\begin{tabular}{lcccc}
\hline Path & $\boldsymbol{\beta}$ & STDEV & $\boldsymbol{t}$-values & CI (LL, UL) \\
\hline Conscientiousness $\rightarrow$ EPM & 0.348 & 0.091 & 3.838 & $0.167,0.471$ \\
EPM $\rightarrow$ Work Passion & 0.311 & 0.073 & 4.093 & $0.182,0.388$ \\
Extraversion $\rightarrow$ EPM & 0.301 & 0.076 & 3.956 & $0.145,0.403$ \\
Conscientiousness $\rightarrow$ EPM $\rightarrow$ Work Passion & 0.108 & 0.044 & 2.500 & $0.023,0.177$ \\
Extraversion $\rightarrow$ EPM $\rightarrow$ Work Passion & 0.094 & 0.037 & 2.468 & $0.023,0.150$ \\
\hline
\end{tabular}

Table 5: Results of VIF, f2, R2 and Q2.

\begin{tabular}{lcccc}
\hline Latent Constructs & VIF & $\boldsymbol{f}^{\mathbf{2}}$ & $\mathbf{R}^{\mathbf{2}}$ & $\boldsymbol{Q}^{\mathbf{2}}$ \\
\hline EPM & 1 & 0.107 & 0.279 & 0.146 \\
Work Passion & & & 0.097 & 0.039 \\
Conscientiousness & 1.116 & 0.151 & & \\
Extraversion & 1.116 & 0.113 & & \\
\hline
\end{tabular}

\section{Discussion}

The aim of this study was to find out the relationship between personality, perceived EPM as developmental and Work Passion, and to identify whether the EPM mediates the relationship of personality and Work Passion. An extensive amount of study is conducted on personality and Work Passion, but very few studies are conducted on the EPM perceived as developmental, it is mentioned that the last systematic study on this area was done in 2000 (Ravid, 2020). EPM is conceptualized as predictor of work 
attitudes and behaviors (Davidson \& Henderson, 2000), productivity and task performance (Nebeker \& Tatum, 1993). The early research considers EPM as unidimensional and associated it with negative and decreased performance (Smith et al., 1992). With the passage of time, the scholars extended their research and started exploring the different aspects of the EPM such as timing (Watson et al., 2013) purpose (Bartels \& Nordstrom, 2012), target (Ambrose \& Alder, 2000), scope and control (Moorman \& Wells, 2003; McNall \& Stanton, 2011). Whereas the relationship between personalities, perception of EPM as developmental and Work Passion is still not studied well. Thus, this study extends the existing literature of personality, EPM and Work Passion by identifying the relationship of them altogether. The previous studies identified positive relationship of developmental EPM and employee attitudes (Holman et al., 2002; Wells et al., 2007). Whereas the mediating effect of developmental EPM have not been studied in the relationship of personality and Work Passion.

The first hypothesis (H1a) was supported by the findings in call centers' employees that means call operators with high conscientiousness perceive EPM as developmental such as for constructive feedback and growth thus increasing their willingness to work which results in increase in their Work Passion. Call center organizations are highly pressured environment therefore, it is beneficial to use EPM as developmental to reduce the negative outcomes of electronic monitoring (Wells et al., 2007). The finding support the second hypothesis ( $\mathrm{H} 1 \mathrm{~b})$ which identified that extroverts do not tend to perceive EPM as detrimental and consider it's positive aspects and are more concerned about the performance (Clark \& Watson, 1991).

The result of the third hypothesis (H2) demonstrated that developmental EPM is a source of producing Work Passion among employees. As mentioned earlier that the existence of EPM delivers positive outcomes (Bartels \& Nordstrom, 2012). It has been identified that EPM without any purpose produces fewer positive outcomes among employees (Ravid, 2020). Hence, when employees perceive EPM as developmental their passion for work is increased and it supported our assumptions.

The fourth hypothesis (H3a: EPM perceived as developmental mediates the relationship between Conscientiousness and Work Passion of employees) is also supported by the findings. It identified that personality is a predictor of the behaviors of employee when there is use of EPM in the organizations (Ravid, 2020). For Conscientiousness, employees with such personality characteristics showed that they perceive EPM as developmental when being monitored electronically (Zweig \& Webster, 2003).

Our last hypothesis (H3b) is also supported by our findings. For Extraversion, it has been identified that they are more acceptable of EPM and perceive it as developmental and are satisfied with the managerial justifications of the EPM (Chen \& Ross, 2007). The effects of personality characteristics become positive when they find themselves in EPM settings because perception of EPM as developmental triggers the high selfdeterminant state out of employees which results into the increased Work Passion. Personality has significant effect on electronic monitoring perception some personality traits perceive developmental as positive which in return enhances their positive attitude towards work. 


\section{Limitations and Future Directions}

We believe that the findings of this study highlight numerous future avenues of research. Our study examined the idea that the use of EMP as developmental tool is associated with positive attitudes at work. However, it is not clear to what extent this is true for different purposes of EMP. Second, this research has considered the effect of EPM directed downwards towards the employees. There is a need to consider the multidirectional nature of EPM. Future research may consider the effect of EPM on mangers and how different personalities of managers perceive EPM as a useful tool or as a threat to their control and autonomy. Third, the results are based on the sample taken from the call centers. Therefore, generalizing the findings of this study to other sectors is also required.

In addition, this study was conducted during the period of covid-19. The pandemic has affected almost all the sectors including call centers. Few of the call centers contacted had resumed their operations due to pandemic. So, a study during normal circumstances might provide useful insights. We used an online survey, which might bias our results. Future studies should explore different survey strategies to reduce sampling and data collection biases. Lastly the study used only one mediator. Future research can incorporate moderators to test the strength of relationships between personality traits, EPM and work attitudes.

\section{Practical Implications for Asian Managers}

The research model proposed in this paper provides several recommendations for Asian managers. In particular, the results of the study would help Asian human resources professionals effectively perform many human resources functions, such as employee staffing, training, and performance management system. The results suggest that call operators with high on conscientiousness and extraversion perceive EPM as a development tool. Human resource managers may consider selecting employees with high conscientiousness and extraversion at the time of recruitment and selection. Because individuals with these personality traits tend to perceive EPM as developmental. As a result, organizations will have lower employee turnover and a healthy work environment.

In addition, this study would help HR professionals develop specific training programs. In so doing, they must plan these programs in accordance with employees' individual differences. This intervention is very necessary due to a stressful work environment in call centers as it will motivate employees and reduce the number of employees' complaints. In long run, such an intervention may help in increasing employees' level of engagement and reduce staff turnover.

The second recommendation for Asian managers is to consider users personality traits when designing a performance monitoring system. The spread of technology in the workplace is increasing rapidly and become a necessity. Currently, many employees in Asia, especially in call centers, are working with technologies that track call operators call time, and behavior toward customers. As findings of the present study indicate that individual differences are an important factor in predicting positive results associated with the use of EPM. To reduce the negative impact of the use of EPM, employers must 
take into account the personality of the users and characteristic of the EPM system when designing performance management systems. An inclusive approach can be useful, as it involves all stakeholders before designing a system and then keeping them informed at the design and pre-test stages. Such inclusiveness will lead employees to own the system and less resistance to change, which will lead to positive behaviors in the workplace.

This study also reveals that the perceived purpose of EPM as developmental mediates the relationship between consciousness and extraversion and work passion. In other words, employees high on conscientiousness and extraversion perceive EPM as useful in developing their skills and abilities instead of being a cause of stress. Therefore, in order to reduce employees' negative reactions to the use of EPM, HR managers need to find different ways to communicate the purpose of EPM so that employees consider it a positive intervention that will help them improve their skills and capabilities.

Additionally, managers need to activate organizational communication channels so that employees know the advantages of an effective EPM system and how they will help employees to progress in the current roles as well as in future responsibilities. One way to do this is to organize regular awareness sessions, such as meeting, workshops, and seminars with clear objective to educate employees and respond their concerns regarding the EPM. As the working environment in call centers usually believed as a stressful environment, a top-down communication strategy will do wonders in terms of clarifying their doubts, thereby increasing their satisfaction with the EPM system.

\section{References}

Abraham, M., Niessen, C., Schnabel, C., Lorek, K., Grimm, V., Möslein, K., \& Wrede, M. (2019). Electronic monitoring at work: The role of attitudes, functions, and perceived control for the acceptance of tracking technologies. Human Resource Management Journal, 29(4), 657-675.

Aiello, J. R., \&Svec, C. M. (1993). Computer monitoring of work performance: Extending the social facilitation framework to electronic presence 1. Journal of Applied Social Psychology, 23(7), 537-548.

Alessandri, E., Rose, D., \&Wasley, D. (2020). Health and Wellbeing in Higher Education: A comparison of music and sport students through the framework of Self Determination Theory. Frontiers in psychology, 11(1), 1-19.

Ambrose, M. L., \& Alder, G. S. 2000. Designing, implementing, and utilizing computerized performance monitoring: Enhancing organizational justice. Research in Personnel and Human Resources Management, 18: 187-220.

Anderson, J. C., \&Gerbing, D. W. (1988). Structural equation modeling in practice: A review and recommended two-step approach. Psychological bulletin, 103(3), 411-423.

Ariani, D. W. (2013). Personality and learning motivation. European Journal of Business and Management, 5(10), 26-38.

Ariani, D. W. (2013). The relationship between employee engagement, organizational citizenship behavior, and counterproductive work behavior. International Journal of Business Administration, 4(2), 46-56.

Athota, V. S., Budhwar, P., \& Malik, A. (2020). Influence of personality traits and moral values on employee well-being, resilience and performance: A cross-national study. Applied Psychology, 69(3), 653-685.

Avkiran, N. K. (2018). An in-depth discussion and illustration of partial least squares structural equation modeling in health care. Health care management science, 21(3), 401-408. 
Bakker, A. B., Tims, M., \& Derks, D. (2012). Proactive personality and job performance: The role of job crafting and work engagement. Human relations, 65(10), 1359-1378.

Baloch, F. (2018, June 25). Pakistan, the next outsourcing hub. Profit by Pakistan Today, https://profit.pakistantoday.com.pk/2018/06/25/pakistan-the-next-outsourcing-hub/

Bartels, L. K., \& Nordstrom, C. R. 2012. Examining big brother's purpose for using EPM. Performance Improvement Quarterly, 25(1), 65-77.

Baum, J. R., \& Locke, E. A. (2004). The relationship of entrepreneurial traits, skill, and motivation to subsequent venture growth. Journal of applied psychology, 89(4), 587.

Becker, T.E. (2005), "Potential problems in the statistical control of variables in organizational research: a qualitative analysis with recommendations", Organizational Research Methods, Vol. 8 No. 3, pp. 274-289.

Becker, W. J., Belkin, L. Y., Conroy, S. A., \&Tuskey, S. (2019). Killing Me Softly: Organizational E-mail Monitoring Expectations' Impact on Employee and Significant Other Well-Being. Journal of Management, 20(10), 1-29

Bélanger, J. J., Lafrenière, M. A. K., Vallerand, R. J., \&Kruglanski, A. W. (2013). When passion makes the heart grow colder: The role of passion in alternative goal suppression. Journal of Personality and Social Psychology, 104(1), 126-147.

Blickle, G., Meurs, J. A., Wihler, A., Ewen, C., Merkl, R., \&Missfeld, T. (2015). Extraversion and job performance: How context relevance and bandwidth specificity create a nonlinear, positive, and asymptotic relationship. Journal of vocational behavior, 87, 80-88.

Brown, A. R., Badger, J. M., Behrend, T. S., \& Jensen, J. M. (2012, April). Personality Predicts Acceptance of Performance Monitoring at Work. Paper presented to the 27th Annual Meeting of the Society for Industrial and Organizational Psychology, San Diego, CA.

Chen, J. V., \& Ross, W. H. (2007). Individual differences and electronic monitoring at work. Information, Community and Society, 10(4), 488-505.

Chen, P., Lee, F., \& Lim, S. (2020). Loving thy work: Developing a measure of Work Passion. European Journal of Work and Organizational Psychology, 29(1), 140-158.

Chung, N., Koo, C., \& Kim, J. K. (2014). Extrinsic and intrinsic motivation for using a booth recommender system service on exhibition attendees' unplanned visit behavior. Computers in Human Behavior, 30, 59-68.

Clark, L. A., \& Watson, D. (1991). General affective dispositions in physical and psychological health. Handbook of social and clinical psychology, 12, 221-245.

Claypoole, V. L., \&Szalma, J. L. (2019). EPM and sustained attention: Social facilitation for modern applications. Computers in Human Behavior, 94, 25-34.

Claypoole, V. L., Neigel, A. R., Fraulini, N. W., Hancock, G. M., \&Szalma, J. L. (2018). Can vigilance tasks be administered online? A replication and discussion. Journal of Experimental Psychology: Human Perception and Performance, 44(9), 1348-1355.

Claypoole, V. L., Waldfogle, G. E., Neigel, A. R., \&Szalma, J. L. (2018, September). Exploring the effects of Extraversion on social facilitation and vigilance task performance. In Proceedings of the Human Factors and Ergonomics Society Annual Meeting, 62(1), 1216-1220.

Cleveland, J. N., Murphy, K. R., \& Williams, R. E. (1989). Multiple uses of performance appraisal: Prevalence and correlates. Journal of applied psychology, 74(1), 130.

Connelly, C. E., Fieseler, C., Černe, M., Giessner, S. R., \& Wong, S. I. (2020). Working in the digitized economy: HRM theory \& practice. Human Resource Management Review, 100762

Costa, P. T., \& McCrae, R. R. (1992). Normal personality assessment in clinical practice: The NEO Personality Inventory. Psychological assessment, 4(1), 5-13.

Costa Jr, P. T., McCrae, R. R., \&Löckenhoff, C. E. (2019). Personality across the life span. Annual review of psychology, 70, 423-448.

Dalpé, J., Demers, M., Verner-Filion, J., \& Vallerand, R. J. (2019). From personality to passion: The role of the Big Five factors. Personality and Individual Differences, 138, 280-285.

Davidson, R., \& Henderson, R. 2000. EPM: A laboratory investigation of the influence of monitoring and difficulty on task performance, mood state, and self-reported stress levels. Journal of Applied Social Psychology, 30, 906-920. 
Deci, E. L., \& Ryan, R. M. (2008). Self-determination theory: A macro theory of human motivation, development, and health. Canadian psychology/PsychologyCanadienne, 49(3), 182-185.

Deci, E. L., \& Ryan, R. M. (2012). Motivation, personality, and development within embedded social contexts: An overview of self-determination theory. The Oxford handbook of human motivation, 85-107.

DeYoung, C. G., Quilty, L. C., \& Peterson, J. B. (2007). Between facets and domains: 10 aspects of the Big Five. Journal of Personality and Social Psychology, 93, 880 - 896.

Donnellan, M. B., Oswald, F. L., Baird, B. M., \& Lucas, R. E. (2006). The mini-IPIP scales: tiny-yet-effective measures of the Big Five factors of personality. Psychological assessment, 18(2), 192.

Dumlao, S. V., Mendoza, A. M., \& Payne, S. C. Performance Monitoring in the 21st Century. Encyclopedia of Electronic HRM, 182.

Durrani, M. F. A. K. (2018). Analysis of Business Process Outsourcing in Pakistan. Journal of Information Communication Technologies and Robotic Applications, 49-57.

Flint, D., Haley, L. M., \& McNally, J. J. (2013). Individual and organizational determinants of turnover intent. Personnel Review, 42, 552-572.

Fornell, C., \&Larcker, D. F. (1981). Evaluating structural equation models with unobservable variables and measurement error. Journal of marketing research, 18(1), 39-50.

Frieder, R. E., Wang, G., \& Oh, I. S. (2018). Linking job-relevant personality traits, transformational leadership, and job performance via perceived meaningfulness at work: A moderated mediation model. Journal of Applied Psychology, 103(3), 324-333.

Fuller, C. M., Simmering, M. J., Atinc, G., Atinc, Y., \&Babin, B. J. (2016). Common methods variance detection in business research. Journal of Business Research, 69(8), 31923198.

Furnham, A., \& Swami, V. (2015). An Investigation of Attitudes toward Surveillance at Work and Its Correlates. Psychology, 6, 1668-1675

Fusi, F., \& Feeney, M. K. (2018). Electronic monitoring in public organizations: evidence from US local governments. Public Management Review, 20(10), 1465-1489.

Goldberg, L. R. (1990). An alternative" description of personality": the big-five factor structure. Journal of personality and social psychology, 59(6), 1216-1229.

Gridwichai, P., Kulwanich, A., Piromkam, B., \&Kwanmuangvanich, P. (2020). Role of Personality Traits on Employees Job Performance in Pharmaceutical Industry in Thailand. Systematic Reviews in Pharmacy, 11(3), 185-194.

Hair, J.F., Hult, G.T.M., Ringle, C.M. and Sarstedt, M. (2014), A Primer on Partial Least Squares Structural Equation Modeling (PLS-SEM), SAGE, Los Angeles, CA.

Hair, J.F., Hult, G.T.M., Ringle, C.M. and Sarstedt, M. (2017), A Primer on Partial Least Squares Structural Equation Modeling (PLS-SEM), 2nd ed., Sage, Thousand Oaks, CA.

Haq, I. U., De Clercq, D., \& Azeem, M. U. (2019). Can employees perform well if they fear for their lives? Yes-if they have a passion for work. Personnel Review, 1-22.

Heerwegh, D. (2009). Mode differences between face-to-face and web surveys: an experimental investigation of data quality and social desirability effects. International Journal of Public Opinion Research, 21(1), 111-121.

Ho, V. T., \& Astakhova, M. N. (2020). The passion bug: How and when do leaders inspire Work Passion? Journal of Organizational Behavior, 41(5), 424-444.

Holman, D., Chissick, C., \&Totterdell, P. 2002. The effects of performance monitoring on emotional labor and well-being in call centers. Motivation and Emotion, 26, 57-81.

Jahagirdar, R., \&Bankar, S. (2020). EMPLOYEES PERCEPTION OF WORKPLACE MONITORING AND SURVEILLANCE. PEOPLE: International Journal of Social Sciences, 6(1).

Jeske, D., \& Kapasi, I. (2018). EPM: Lessons from the Past and Future Challenges. In Organizing for digital economy: Societies, communities and individuals. Proceedings of the 14th annual conference of the Italian chapter of the AIS, 19-132.

Jeske, D., \&Santuzzi, A. M. (2013). Effect of monitoring techniques on job attitudes, control, 
intentions and behaviors at work. In Proceedings of the IADIS international conference on e-Society, 266-274.

John, O. P., Naumann, L. P., \& Soto, C. J. (2008). Paradigms shift to the integrative big five trait taxonomy. Handbook of personality: Theory and research, 3(2), 114-158.

Junglas, I. A., Johnson, N. A., \&Spitzmüller, C. (2008). Personality traits and concern for privacy: an empirical study in the context of location-based services. European Journal of Information Systems, 17(4), 387-402.

Jeske, D., \&Santuzzi, A. (2015). Monitoring what and how: Psychological implications of electronic performance monitoring. New Technology, Work and Employment, 30 (1), 62- 78 .

Karim, M. N. (2015). Electronic monitoring and self-regulation: Effects of monitoring purpose on goal state, feedback perceptions, and learning (Doctoral dissertation, The George Washington University).

Kraemer, T., \&Gouthier, M. H. J. (2014). How organizational pride and emotional exhaustion explain turnover intentions in call centers. A multi-group analysis with gender and organizational tenure. Journal of Service Management, 25(1), 125- 148. doi:10.1108/JOSM-07-2013-0173

Krupić, D., \&Corr, P. J. (2020). How reinforcement sensitivity theory relates to selfdetermination theory. Personality and Individual Differences, 155, 1-5.

Kreil, A., Tumasjan, A., Yasseri, T., \&Welpe, I. (2021). What drives passion? An empirical examination on the impact of personality trait interactions and job environments on Work Passion. arXiv preprint arXiv:2101.01270. 1-29.

Kumar, N. (2019). Determinants of stress and well-being in call centre employees. Journal of Management, 6(2), 19-24.

Kumar, N., Isa, F. M., Hin, C. W., \& Abdullah, H. H. (2012). Development of a framework for services recovery for service industries. Journal for Global Business Advancement, 5(2), 89-102.

Laird, B. K., Bailey, C. D., \& Hester, K. (2018). The effects of monitoring environment on problem-solving performance. The Journal of social psychology, 158(2), 215-219.

Lalande, D., Vallerand, R. J., Lafrenière, M.-A. K., Verner-Filion, J., Laurent, F.-A., Forest, J., \& Paquet, Y. (2017). Obsessive passion: A compensatory response to unsatisfied needs. Journal of Personality, 85, 163-178.

Liang, H., Xue, Y., \& Wu, L. (2013). Ensuring employees' it compliance: Carrot or stick? Information Systems Research, 24(2), 279-294.

Dahlhamer, J., Lucas, J., Zelaya, C., Nahin, R., Mackey, S., DeBar, L., ... \& Helmick, C. (2018). Prevalence of chronic pain and high-impact chronic pain among adults - United States, 2016. Morbidity and Mortality Weekly Report, 67(36), 1001-1006.

McCrae, R. R., \& Costa Jr, P. T. (1991). Adding Liebe und Arbeit: The full five-factor model and well-being. Personality and social psychology bulletin, 17(2), 227-232.

McNall, L. A., \& Stanton, J. M. 2011. Private eyes are watching you: Reactions to location sensing technologies. Journal of Business and Psychology, 26, 299-309.

Memon, M. A., Ting, H., Cheah, J.-H., Thurasamy, R., Chuah, F., \& Cham, T. H. (2020). Sample Size for Survey Research: Review and Recommendations. Journal of Applied Structural Equation Modeling, 4(2), 1-20.

Moussa, M. (2015). Monitoring employee behavior through the use of technology and issues of employee privacy in America. Sage Open, 5(2), 1-13.

Moorman, R. H., \& Wells, D. L. 2003. Can EPM be fair? Exploring relationships among monitoring characteristics, perceived fairness, and job performance. Journal of Leadership \& Organizational Studies, 10, 2-16.

Morris, S., Griffin, D., \& Gower, P. 2017. Barclays puts in sensors to see which bankers are at their desks. Bloomberg. Retrieved from https://www.bloomberg.com/news/articles /2017-08-18/barclays-puts-in-sensors-to-see-which-bankers-are-at-their-desks.

Nebeker, D. M., \& Tatum, B. C. (1993). The Effects of Computer Monitoring, Standards, and Rewards on Work Performance, Job Satisfaction, and Stress 1. Journal of Applied Social Psychology, 23(7), 508-536. 
Nitzl, C., Roldan, J. L., \& Cepeda, G. (2016). Mediation analysis in partial least squares path modeling: Helping researchers discuss more sophisticated models. Industrial management \& data systems. 116(9), 1849-1864.

Noguchi, K., Gohm, C. L., \&Dalsky, D. J. (2006). Cognitive tendencies of focusing on positive and negative information. Journal of Research in Personality, 40(6), 891-910.

Olafsen, A. H., Halvari, H., Forest, J., \& Deci, E. L. (2015). Show them the money? The role of pay, managerial need support, and justice in a self-determination theory model of intrinsic work motivation. Scandinavian journal of psychology, 56(4), 447-457.

Pietrabissa, G., Rossi, A., Borrello, M., Manzoni, G. M., Mannarini, S., Castelnuovo, G., \& Molinari, E. (2020). Development and validation of a self-determination theory-based measure of motivation to exercise and diet in children. Frontiers in psychology, 11, 116.

Pollack, J. M., Ho, V. T., O'Boyle, E. H., \& Kirkman, B. L. (2020). Passion at work: A metaanalysis of individual work outcomes. Journal of Organizational Behavior, 41(4), 311331.

Ravid, D. M., Tomczak, D. L., White, J. C., \& Behrend, T. S. (2020). EPM 20/20: A review, framework, and research agenda for EPM. Journal of Management, 46(1), 100-126.

Rigby, C. S., \& Ryan, R. M. (2018). Self-determination theory in human resource development: New directions and practical considerations. Advances in Developing Human Resources, 20(2), 133-147.

Ringle, C. M., Wende, S., \& Becker, J. M. (2015). SmartPLS 3. SmartPLS GmbH. Bönningstedt, Germany.

Roberts, B. W., Jackson, J. J., Fayard, J. V., Edmonds, G., \&Meints, J. (2009). Conscientiousness. In M. R. Leary \& R. H. Hoyle (Eds.), Handbook of individual differences in social behavior, 369-381.

Robinson, C. (2020). EPM effects on workplace well-being: The role of personality (Doctoral dissertation, The University of Waikato).

Samaranayake, V., \& Gamage, C. (2012). Employee perception towards electronic monitoring at workplace and its impact on job satisfaction of software professionals in Sri Lanka. Telematics and Informatics, 29(2), 233-244.

Samee, N. (2020). The Moderating Role of Agreeableness and Conscientiousness on the Relationships Between Burnout and Withdrawal Behaviors (Doctoral dissertation, San Jose State University), 1-72.

SARI, Y. (2020). Predictors of Job Performance: Moderating Role of Conscientiousness. International Journal of Innovation, Creativity and Change, 1-18.

Saunders, Mark, Lewis, Philip, and Thornhill, Adrian. (2007). Research Methods for Business Students (4 ed.). England: Prentice Hall.

Sayre, G. M., \&Dahling, J. J. (2016). Surveillance 2.0: How personality qualifies reactions to social media monitoring policies. Personality and Individual Differences, 90, 254-259.

Schneider, T. J., Goffin, R. D., \&Daljeet, K. N. (2015). "Give us your social networking site passwords": Implications for personnel selection and personality. Personality and Individual Differences, 73, 78-83.

Schwarz, A., Rizzuto, T., Carraher-Wolverton, C., Roldán, J. L., \& Barrera-Barrera, R. (2017). Examining the impact and detection of the" urban legend" of common method bias. ACM SIGMIS Database: The DATABASE for Advances in Information Systems, 48(1), 93-119.

Sherif, K., \&Jewisimi, O. (2018). EPM Friend or Foe: Empowering Employees through Data Analytics.

Sinkovics, R. R., Richter, N. F., Ringle, C. M., \&Schlägel, C. (2016). A critical look at the use of SEM in international business research. International marketing review, 33(3), 376404.

Smith, M. J., Carayon, P., Sanders, K. J., Lim, S. Y., \&LeGrande, D. 1992. Employee stress and health complaints in jobs with and without EPM. Applied Ergonomics, 23: 17-27.

Smith, M. J., Carayon, P., Sanders, K. J., Lim, S. Y., \&LeGrande, D. (1992). Employee stress and health complaints in jobs with and without EPM. Applied ergonomics, 23(1), 17- 
27.

Stone, D. L. (1986). Relationship between introversion/Extraversion, values regarding control over information, and perceptions of invasion of privacy. Perceptual and Motor Skills, 62(2), 371-376.

Story, J., \&Castanheira, F. (2020). How hybrid HR systems affect performance in call centers. Personnel Review, 1-17.

The U.S. Bureau of Labor Statistics. (2015). Employment projections: 2014-24 summary. Retrieved from http://www.bls.gov/news.release/ecopro.nr0.htm

Thibault-Landry, A., Egan, R., Crevier-Braud, L., Manganelli, L., \& Forest, J. (2018). An empirical investigation of the employee Work Passion appraisal model using selfdetermination theory. Advances in Developing Human Resources, 20(2), 148-168.

Thompson, L. F., Sebastianelli, J. D., \& Murray, N. P. (2009). Monitoring Online Training Behaviors: Awareness of Electronic Surveillance Hinders E-Learners 1. Journal of Applied Social Psychology, 39(9), 2191-2212.

Tomczak, D. L., Lanzo, L. A., \&Aguinis, H. (2018). Evidence-based recommendations for employee performance monitoring. Business Horizons, 61(2), 251-259.

Umar, T. R., Yammama, B. A., \&Shaibu, R. O. (2020). The Implications of Adopting and Implementing Electronic Human Resource Management Practices on Job Performance. Journal of Human Resource Management, 8(2), 96-108.

Vallerand, R. J., Blanchard, C., Mageau, G. A., Koestner, R., Ratelle, C., Léonard, M., Marsolais, J. (2003). Les passions de l'ame: On obsessive and harmonious passion. Journal of Personality and Social Psychology, 85, 756-767.

Vallerand,R. J., \& Houlfort,N. (Eds.). (2019). Passion for Work: Theory, Reseach, and Applications. Oxford University Press.

Watson, A. M., Foster Thompson, L., Rudolph, J. V., Whelan, T. J., Behrend, T. S., \&Gissel, A. L. (2013). When big brother is watching: Goal orientation shapes reactions to electronic monitoring during online training. Journal of Applied Psychology, 98: 642657.

Wells, D. L., Moorman, R. H., \& Werner, J. M. (2007). The impact of the perceived purpose of EPM on an array of attitudinal variables. Human Resource Development Quarterly, 18(1), 121-138.

White, J. C., Ravid, D. M., \& Behrend, T. S. (2020). Moderating effects of person and job characteristics on digital monitoring outcomes. Current opinion in psychology, 31, 5560 .

Ye, H., Luedtke, J., \& Shen, H. (2019). Call center arrivals: When to jointly forecast multiple streams? Production and Operations Management, 28(1), 27-42.

Yost, A. B., Behrend, T. S., Howardson, G., Darrow, J. B., \& Jensen, J. M. (2019). Reactance to electronic surveillance: a test of antecedents and outcomes. Journal of Business and Psychology, 34(1), 71-86.

Zacher, H. (2014). Individual difference predictors of change in career adaptability over time. Journal of Vocational Behavior, 84(2), 188-198.

Zweig, D., \& Webster, J. (2003). Personality as a moderator of monitoring acceptance. Computers in Human Behavior, 19(4), 479-493. 